\title{
Diversity Studies for Anaerobic Germination in Rice (Oryza sativa L.)
}

\author{
R. Arulmozhi ${ }^{1 *}$, A. JohnJoel ${ }^{1}$, R. Suresh ${ }^{1}$, P. Boominathan ${ }^{2}$ and K. Sathiya Bama ${ }^{1}$ \\ ${ }^{1}$ Tamil Nadu Rice Research Institute, Aduthurai, Tanjavur-612101, India \\ ${ }^{2}$ Agricultural College and Research Institute, Eachangkottai, Tanjavur-614 902, India
}

*Corresponding author

\begin{tabular}{|l|}
\hline Ke y w or d s \\
Anaerobic \\
Germination, \\
Coleoptile \\
Elongation, Direct \\
Seeded Rice, \\
Seedling vigour \\
index \\
\hline Article Info \\
\hline $\begin{array}{l}\text { Accepted: } \\
\text { 08 June } 2020 \\
\text { Available Online: } \\
\text { 10 July } 2020\end{array}$ \\
\hline
\end{tabular}

A B S T R A C T

Direct seeding of rice (DSR) is increasingly being practiced in both rainfed and irrigated areas because of labour shortage for transplanting and dwindling freshwater resource. However, poor crop establishment under DSR remains a major obstacle under adverse effects of climatic condition due to lack of germination ability under anaerobic condition necessitates developing multiple stress tolerant varieties. A potted experiment was carried out in the net house of the Plant Breeding Unit, TRRI, Aduthurai in 2020 to screen and evaluate the performance of diverse rice genotypes for anaerobic germination ability with a view to select the suitable genotypes for multiple stress tolerance (drought and anaerobic germination) that will fit into the existing niche in the DSR. The aim of this experiment is to identify short duration genotypes with early vigour and potential to germinate under anaerobic condition. Among the twenty five genotypes screened for anaerobic germination and subjected to cluster analysis showed two genotypes viz., TKM 5 and Norungan which recorded more than $70 \%$ germination grouped in cluster II of total four clusters with increased seedling vigour index. Other notable differences like absence of coleoptile emergence and coleoptile elongation were observed in the drought tolerant donor Apo and submergence tolerant donor FR13A. These results indicate that success of genotype for anaerobic germination mainly depends on the physiological and biochemical mechanism behind coleoptile emergence and coleoptile elongation under deprived oxygen condition.

\section{Introduction}

Rice is the world's most important cereal crop and staple food for about four billion people globally and about 800 million people of India. It also plays a pivotal role in ensuring food security and livelihood security for millions of small and marginal farmers in South and South East Asia. Paddy known to be cultivated in a wide range of environments (Dokku, Das, \& Rao, 2013) and therefore exposed to various types biotic and abiotic stresses, whose combined effect adversely affect crop loss quantitatively and qualitatively (Pathak et al., 2018).

All the stresses are considered a serious threat to sustainable paddy production. Among that, biotic stress contributes to $37 \%$ of yield loss (Krishnaiah and Varma, 2012) whereas abiotic stresses contribute to $50 \%$ yield loss (Swain et al., 2017). 
Most commonly rainfed environment which comprise about $45 \%$ of the global rice area are prone to drought, submergence, high temperature stress and anoxic condition during germination under erratic climatic conditions (Sripongpangkul et al., 2000). Even though the response of rice under adverse climatic condition is superior to other crops (Ismail et al., 2012), it is most urgent to develop multiple stress tolerant variety to meet the yield demand in future climatic changes.

The dwindling freshwater resource and severity of abiotic stresses such as frequent occurrence of drought and flash flood have forced to adopt direct seeding in rainfedrice cultivation. In recent years, rice production has shifted from transplanting to direct seeding especially in areas of scarce irrigation water and high cost of labour (Pandey \& Valesco, 2002). DSR reduce labour input by as much as $90 \%$ over transplanting and crop growth duration up to 14 days (Pandey, 1995). In spite of these advantages, direct seeding method is handicapped with due to poor seedling establishment and farmers opt repeated replanting their fields, incurring additional costs and running into other problems late in the season (drought), retransplant older seedlings in standing water into heavily damaged areas, or leave their field barren. Breeding cultivars with tolerance of flooding during germination and early seedling establishment will help avoid these problems.

According to Raymond et al., (1985), seeds were grouped into two classes (Starchy and fatty) on basis of their responses to oxygen availability. Starchy seeds were found tolerant toanaerobiosis because they are able to maintain a high energy metabolism under oxygen deficiency when compared with fatty seeds. However, among the cultivated cereals, decline in oxygen concentrations negatively affects oat and barley germination (which starts with root emergence); whereas rice found to behave differently under anoxic condition by suppressed root growth and increase in shoot growth when oxygen concentration declines (Tsuji, 1973; Alpi and Beevers, 1983; Perata and Alpi, 1993; Vartapetian, 2005). Anaerobic germination is one of the most important factor causing yield loss, and the main obstacle for preventing the large-scale adoption of DSR (Hsu \& Tung, 2015) especially in rainfed lowlands where direct seeding is practiced (Kirk et al., 2014; Septiningsih, 2013).Since, anaerobic germination is associated with faster germination and faster coleoptile elongation due to replacement of aerobic respiration by alcoholic fermentation enzymes as a source of energy (Miro et al., 2013).It is an essential adaptation trait for DSR to be successful. Hence, a viable DSR should possess the capacity to germinate anaerobically with enhanced tolerance to flooding during germination and early seedling vigour which will end up with successful crop establishment.

Future rainfed environments demand rice genotypes with multiple abiotic stress tolerance viz., anaerobic germination ability (Miro et al., 2013), early seedling vigour (Balasubramanian and Hill, 2002; Cairns et al., 2009) and tolerance to terminal drought. Most modern rice varieties, either completely fail to germinate under water or fail to elongate the coleoptile and develop roots and shoots for further development under a long period of oxygen deprivation, resulting in partial to complete crop failure (Magneschi and Perata, 2009; Narsai et al., 2015). The present-day task before plant breeders is to identify the genotypes from the germplasm resources which possess anaerobic germination and to introgress the traits into an agronomically superior variety for development of rice pre-breeding lines with 
tolerance to anaerobic conditions during germination coupled with coleoptile elongation and high yield could be a solution for overcoming these constraints (Doley et al., 2018).

But, still information on pre breeding materials for anaerobic germination tolerance or in combination with other stresses is lacking. Therefore this study focuses on two objectives 1) Identification of donors/prebreeding lines for anaerobic germination and 2) Assessing the existing BILs with drought QTLs for anaerobic germination with the view to develop multiple stress tolerant genotypes to be utilized in abiotic stress tolerance breeding programmes.

\section{Materials and Methods}

The experiment was designed to investigate the germination and seedling vigour of 25 selected rice genotypes under anaerobic conditions during the summer, 2020. The anaerobic experiment was carried out inside the net house located in Plant Breeding and Genetics unit of TRRI Aduthurai.

\section{Experimental materials}

The facilities under TRRI, Aduthurai for screening rice genotypes for anaerobic germination were utilized for evaluation of the study material during summer, 2020. The 25 genotypes include landraces, BIL populations and high yielding varieties which were selected based on earlier evaluation and through previous literature studies. The details of the shortlisted reference set of 25 genotypes are given in Table 1.

\section{Germination in normal aerobic condition (Lab Condition)}

Dry uniform seeds (10 seeds/Petri plate) of each genotype were first soaked in $0.1 \%$ solution of Bavistin for 24 hours and the treated seeds were lined in Petri plates filled with water. The excess water from the dishes was drained out at the end of soaking. The seeds were uniformly spaced in Petri dishes and kept in room temperature $\left(35^{\circ} \mathrm{C}\right)$ for 10 days to allow germination and seedling growth. The genotypes were replicated thrice. Ten days after germination under aerobic condition observations on germination percent, coleoptile length, radicle length and number of roots formed were recorded.

\section{Germination in anaerobic condition (Lab Condition)}

Five treated seeds were placed at bottom of $50 \mathrm{ml}$ centrifuge tube, which were filled with water upto $45 \mathrm{ml}$ to create an oxygen-free anaerobic environment. All centrifuge tubes were stacked in racks exposed to $8 \mathrm{~h}$ light and $16 \mathrm{~h}$ dark cycle at room temperature. After ten days, germination under anaerobic condition is measured. Three replicates of centrifuge tubes were performed per genotype. Ten days after germination under anaerobic condition observations on germination percent, coleoptile length, radicle length and number of roots formed were recorded.

\section{Germination in anaerobic condition (Net House)}

Anaerobic germination studies were carried out by following the method reported by Bordoloi \& Sarma, 2018 with slight modifications. Plastic pots of $15 \mathrm{~cm}$ height and $15 \mathrm{~cm}$ diameter were filled with finely powdered field soils of clay loam texture up to a height of $5 \mathrm{~cm}$ after compaction and puddled by adding water before sowing. Soil compaction was measured and followed as per the method reported by Richard et al., 2001. Fungicide treated twenty five seeds were uniformly sown in each pot and gently pressed to a uniform depth of $1 \mathrm{~cm}$ in to the 
puddled soil. Water was slowly poured in to the pots up to a depth of $10 \mathrm{~cm}$ and kept for 20 days to allow germination and seedling growth. The water level in the pots was observed daily morning and evening to maintain a depth of $10 \pm 1 \mathrm{~cm}$ (Figure.1). Twenty days after the anaerobic stress a random sample of five seedlings was considered for recording the various germination and growth traits. Observations on germination percent shoot length, root length, number of roots, seedling length and seedling vigour index were recorded.

\section{Statistical analysis}

Analyses of variance for all the three germination methods were analysed using GENRES 1994 Pascal Intl software version 3.01.Correlation matrix and Euclidean distance matrix was worked out for clustering the 25 genotypes using Multivariate Analysis in STAR statistical software Version 2.0.1. The agglomerative graph was constructed for anaerobic conditions to study the clustering pattern of the 25 rice genotypes.

\section{Results and Discussion}

One of the main objectives of screening for anaerobic germination is to identify anaerobic tolerant genotype. This can be achieved by finding the traits contributing anaerobic germination and screening traits using standard protocols. The main indicative trait used in this study is coleoptile elongation/survival of seedlings under submerged condition. The results of the present study also clearly depict that phenotypic indicator coleoptile elongation is more important than other traits because of significant variation for germination percentage and seedling vigour was measured after imposing anoxic condition Table 2. The presence of significant variation among the twenty five genotypes for coleoptile emergence, coleoptile elongation and absence of radicle development in sensitive genotypes were clearly depicted in the Figure 2 and 3.

These results were in accordance to the earlier findings of Tsuji (1973) on suppressed rice root growth and increase in shoot growth at faster rate than normal to develop hollow coleoptile (the Snorkel effect; Kordan, 1974) with increased aerenchyma cells for efficient internal oxygen transport (Alpi and Beevers, 1983) to submerged parts (Turner et al., 1981) under limited oxygen concentrations and supports more complete and vigorous seedling establishment.

\section{Correlation analysis}

Correlation matrix was performed and observed that all the traits studied showed positive and highly significant correlation with seedling vigour (Table 3 ). The results of correlation matrix revealed that intercorrelation between shoot and root of each individual trait were also found to be highly significant and positive. Similar findings have been reported by Bordoloi and Sarma, 2018. Since all the traits are interrelated and contribute to seedling vigour simultaneous improvement of these traits will end up in genotypes with anaerobic adaptability.

\section{Cluster analysis}

Based on the clustering pattern the twenty five rice genotypes were grouped into four clusters (Figure.5). The drought tolerant genotypes viz., Norungan and TKM 5 which recorded higher germination percent (70$80 \%$ ) and increased seedling vigour under anaerobic germination were grouped in cluster II. The third cluster comprises drought tolerant landraces and varieties viz., Noortipathu, Kuliyadichan, TKM11, PMK2, PMK3 and ANNA(R) 4 with moderate germination of 38 percentage under anoxia. 
Table.1 Experimental genotypes under anaerobic germination (Source: TRRI, Aduthurai)

\begin{tabular}{|c|c|c|c|c|}
\hline Sl. No. & Genotypes & Special Trait & Source & Reference \\
\hline 1. & Norungan & Drought Tolerance landrace & Tamil Nadu & \multirow{3}{*}{$\begin{array}{l}\text { Chandra Babu et al., 2001, } \\
\text { Ganapathy et al., 2010, } \\
\text { Ramanathan } \text { et al., 2018, }\end{array}$} \\
\hline 2. & Kuliyadichan & Drought Tolerance landrace & Tamil Nadu & \\
\hline 3. & Noortipathu & Drought Tolerance landrace & Tamil Nadu & \\
\hline 4. & Apo & $\begin{array}{l}\text { Upland Indica genotype with qDTY1.1, } \\
\text { qDTY2.1, qDTY3.1 and qDTY6.1 } \\
\text { controlling grain yield under stress }\end{array}$ & IRRI, Phillipines & Venu Prasad et al., 2012 \\
\hline 5. & Wayrarem & $\begin{array}{l}\text { Major QTL qDTY } 12.1 \text { for grain yield } \\
\text { under drought }\end{array}$ & Indonesian rice variety & Bernier et al., 2007 \\
\hline 6. & FR13 A & Submergence-tolerantlandrace & Orrisa, India & Xu et al., 2006 \\
\hline 7. & Swarna sub1 & $\begin{array}{l}\text { Submergence Tolerance Sub1 } \\
\text { introgressed variety }\end{array}$ & IRRI, Phillipines & $\begin{array}{l}\text { Neeraja et al., 2007; } \\
\text { Septiningsih } \text { et al., } 2009\end{array}$ \\
\hline 8. & TKM 4 & High yielding variety & RRS, Tirur, Tamil Nadu & \multirow[t]{4}{*}{ Jeyaprakash et al., 2004} \\
\hline 9. & TKM 5 & High yielding variety & RRS, Tirur, Tamil Nadu & \\
\hline 10 & TKM 9 & High yielding variety & RRS, Tirur, Tamil Nadu & \\
\hline 11. & TKM 11 & Drought Tolerant variety & RRS, Tirur, Tamil Nadu & \\
\hline 12. & PMK 2 & Drought Tolerant variety & $\begin{array}{l}\text { ARS, Paramakudi, Tamil } \\
\text { Nadu }\end{array}$ & \multirow{3}{*}{$\begin{array}{l}\text { Chandra Babu et al., 2001, } \\
\text { Ganapathy et al., 2010, } \\
\text { Jeyaprakash } \text { et al., } 2004 \\
\text { Selvaraj } \text { et al., } 2004\end{array}$} \\
\hline 13. & PMK 3 & Drought Tolerant variety & $\begin{array}{l}\text { ARS, Paramakudi, Tamil } \\
\text { Nadu }\end{array}$ & \\
\hline 14. & ANNA (R) 4 & Drought Tolerant variety & $\begin{array}{l}\text { ARS, Paramakudi, Tamil } \\
\text { Nadu }\end{array}$ & \\
\hline 15. & TPS5 & $\begin{array}{l}\text { Short duration variety of high rainfall } \\
\text { zone }\end{array}$ & $\begin{array}{l}\text { ARS, Thirupathisaram, } \\
\text { Tamil Nadu }\end{array}$ & \\
\hline 16. & $\mathrm{CO} 43$ & Saline tolerant variety & $\begin{array}{l}\text { PBS, Coimbatore, Tamil } \\
\text { Nadu }\end{array}$ & SurekhaRao et al., 2008 \\
\hline 17. & ADT (R) 45 & High Yielding and popular variety & $\begin{array}{l}\text { TRRI, Aduthurai, } \\
\text { Tamil Nadu }\end{array}$ & Priyadharshini et al., 2014 \\
\hline 18. & BIL A 37 & qDTY $1.1,3.1$ and 4.1 & $\begin{array}{l}\text { TRRI, Aduthurai, } \\
\text { Tamil Nadu }\end{array}$ & \multirow[t]{4}{*}{$\begin{array}{l}\text { Venu Prasad et al., 2009), } \\
\text { Venu Prasad et al., 2012) }\end{array}$} \\
\hline 19. & BIL A 47 & qDTY $1.1,3.1$ and 4.1 & $\begin{array}{l}\text { TRRI, Aduthurai, } \\
\text { Tamil Nadu }\end{array}$ & \\
\hline 20. & BIL A106 & qDTY $1.1,3.1$ and 4.1 & $\begin{array}{l}\text { TRRI, Aduthurai, } \\
\text { Tamil Nadu }\end{array}$ & \\
\hline 21. & BIL A 127 & qDTY $1.1,3.1$ and 4.1 & $\begin{array}{l}\text { TRRI, Aduthurai, } \\
\text { Tamil Nadu }\end{array}$ & \\
\hline 22. & BIL W 8 & qDTY 12.1 & $\begin{array}{l}\text { TRRI, Aduthurai, } \\
\text { Tamil Nadu }\end{array}$ & \multirow[t]{4}{*}{ Bernier et al., 2007} \\
\hline 23. & BIL W 25 & qDTY 12.1 & $\begin{array}{l}\text { TRRI, Aduthurai, } \\
\text { Tamil Nadu }\end{array}$ & \\
\hline 24. & BILW 50 & qDTY 12.1 & $\begin{array}{l}\text { TRRI, Aduthurai, } \\
\text { Tamil Nadu }\end{array}$ & \\
\hline 25. & BIL W 75 & qDTY 12.1 & $\begin{array}{l}\text { TRRI, Aduthurai, } \\
\text { Tamil Nadu }\end{array}$ & \\
\hline
\end{tabular}

*BIL A - Back Cross Inbred Lines of ADT (R) 45 x Apo

BIL W - Back Cross Inbred Lines of ADT (R) 45 x Wayrarem

RRS-Rice Research Station, ARS-Agricultural Research Station, Triur

PBS- Paddy Breeding Station, Coimbatore

TRRI-Tamil Nadu Rice Research Station, Aduthurai 
Table.2 Analysis of Variance

\begin{tabular}{|c|c|c|c|c|c|c|c|}
\hline Source & df & GP & SHL & RL & NR & SDL & SV \\
\hline Replication & 2 & 77.6538 & 0.4084 & 0.1028 & 0.3600 & 0.8595 & 5.5765 \\
\hline Genotypes & 24 & $1014.54 * *$ & $483.56 * *$ & $31.33 * *$ & $17.93 * *$ & $737.40 * *$ & $179.01 * *$ \\
\hline Error & 48 & 11.8755 & 0.7987 & 0.0747 & 0.4294 & 0.9853 & 1.5455 \\
\hline
\end{tabular}

df- degrees of freedom, GP - Germination per cent, SHL - Shoot Length, RL -Root Length, NR - Number of Roots, SDL - Seedling Length, SV - Seedling Vigour Index

$*$ Significance at $5 \%$ level $\quad * *$ Significance at $1 \%$ level

Table.3 Correlation Matrix

\begin{tabular}{|l|c|c|c|c|c|c|}
\hline Variable & GP & SL & RL & NR & SDL & \multicolumn{1}{|c|}{ SDV } \\
\hline GP & 1 & $0.853^{* *}$ & $0.664 * *$ & $0.643^{* *}$ & $0.827 * *$ & $0.968^{* *}$ \\
\hline SL & & 1 & $0.904 * *$ & $0.770^{* *}$ & $0.996 * *$ & $0.846^{* *}$ \\
\hline RL & & & 1 & $0.711 * *$ & $0.938^{* *}$ & $0.663 * *$ \\
\hline NR & & & & 1 & $0.770 * *$ & $0.542 * *$ \\
\hline SDL & & & & & 1 & $0.822^{* *}$ \\
\hline SDV & & & & & & 1 \\
\hline
\end{tabular}

GP - Germination per cent, SHL - Shoot Length, RL -Root Length,

NR - Number of Roots, SDL - Seedling Length, SV - Seedling Vigour Index

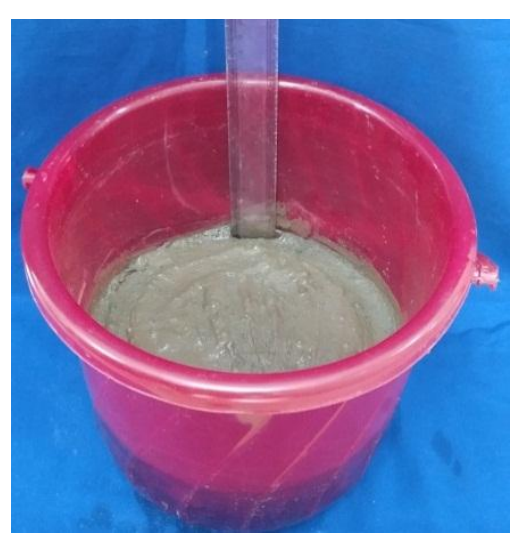

a. Plastic bucket with $5 \mathrm{~cm}$ soil

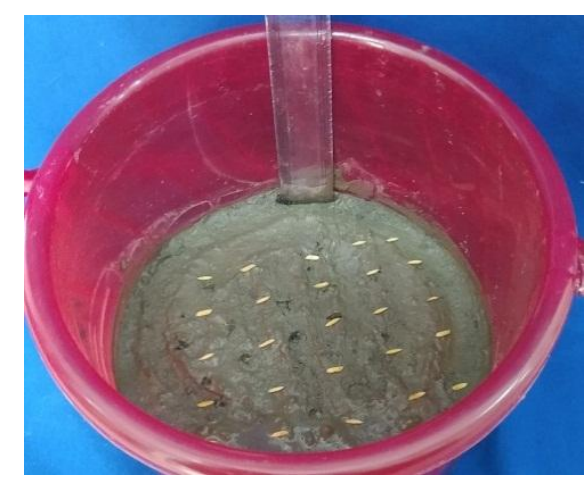

b. 25 seeds placed and pressed to $1 \mathrm{~cm}$ depth

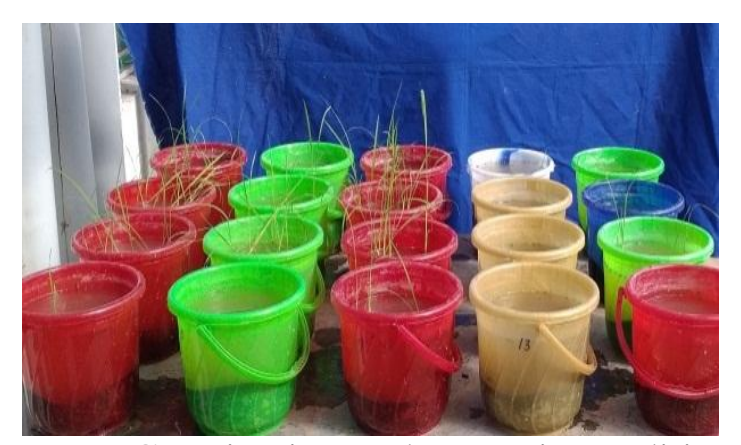

c. Germination under anoxic condition

Fig.1 Anaerobic Screening of Direct Seeded Rice 


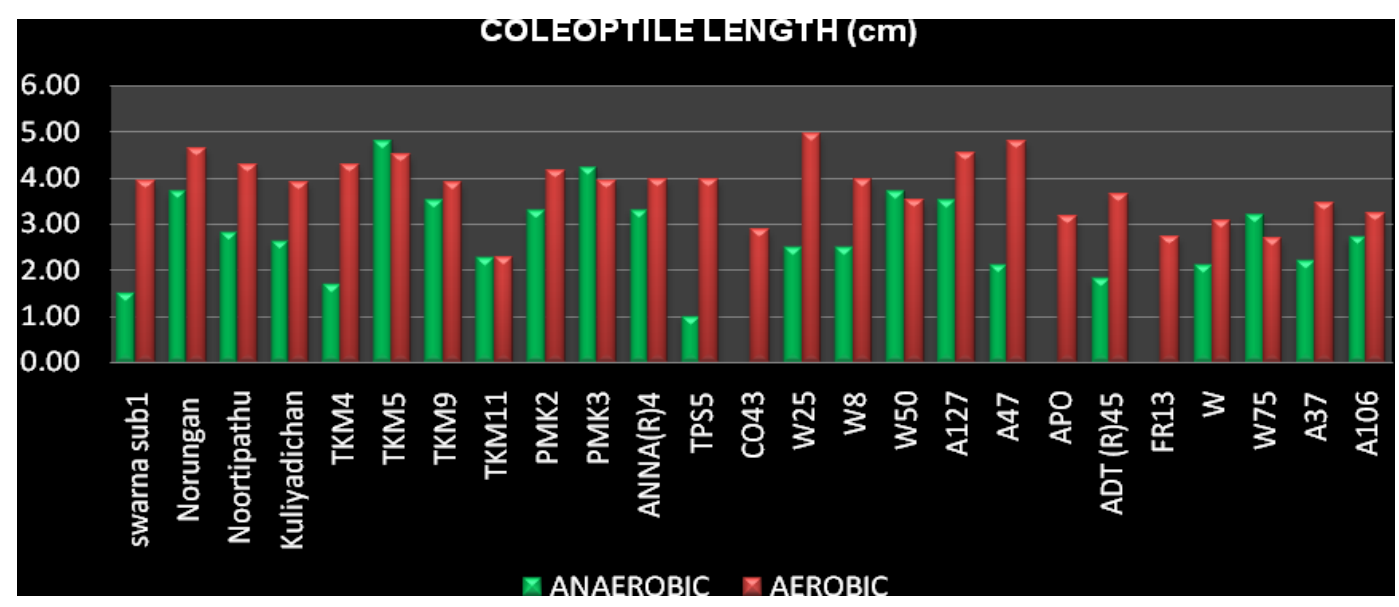

Fig.2 Measure of coleoptile length $(\mathrm{cm})$ under aerobic and anaerobic condition for 25 genotypes

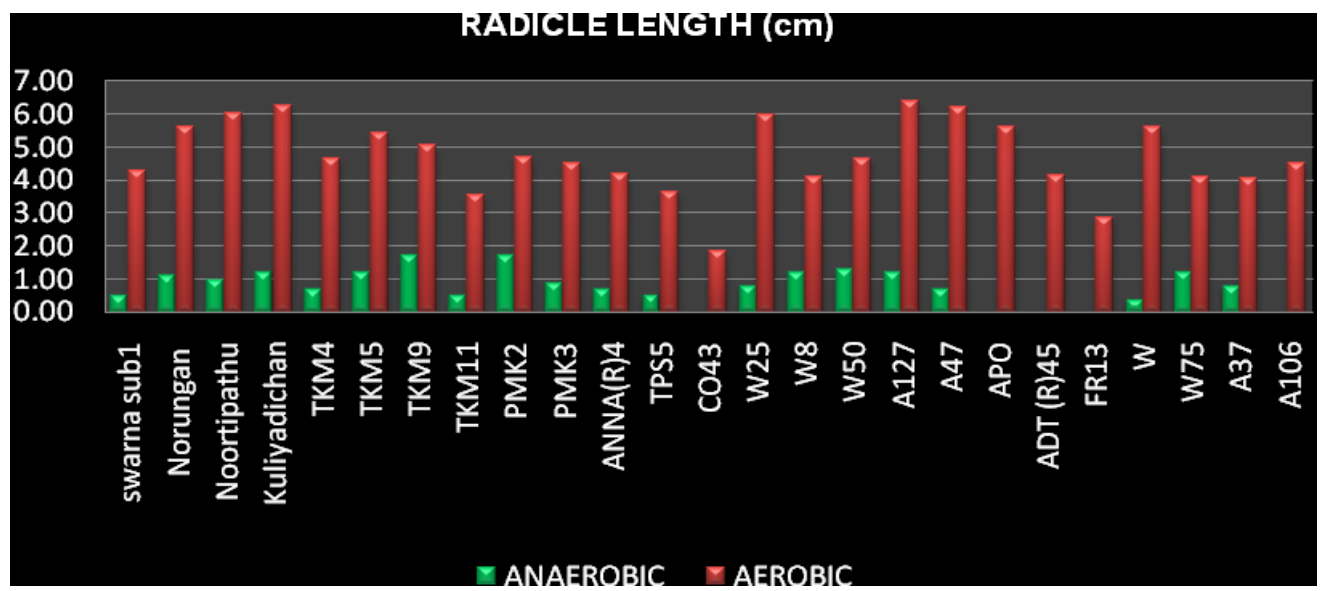

Fig.3 Measure of radicle length $(\mathrm{cm})$ under aerobic and anaerobic condition for 25 genotypes

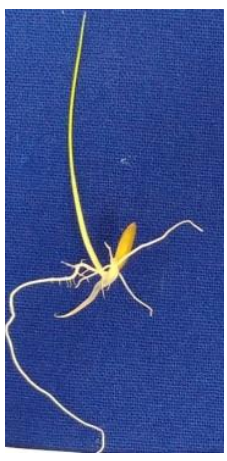

Aerobic condition

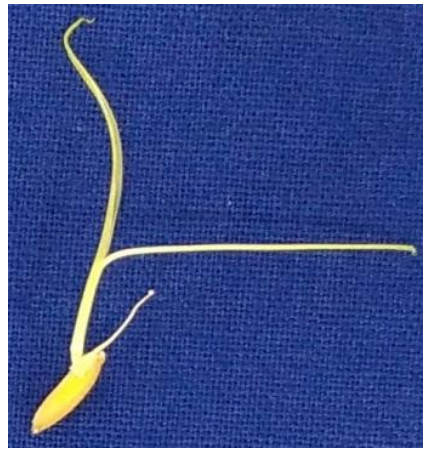

Coleoptile elongation under anaerobic condition

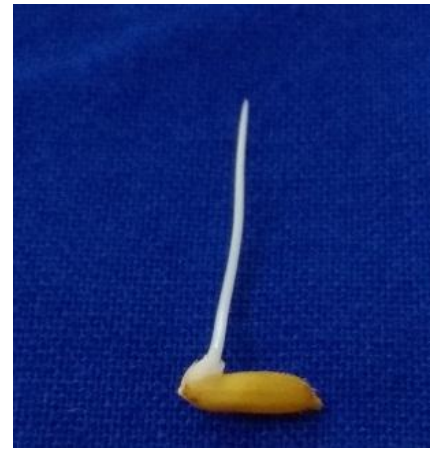

Coleoptile emergence and absence of coleoptile elongation under anaerobic condition

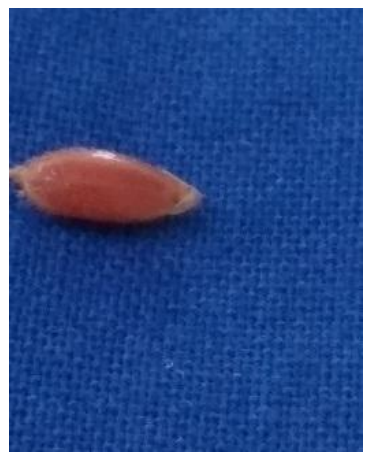

Absence of coleoptile emergence under anaerobic condition

Fig.4 Variation in coleoptile and radicle emergence under aerobic and anaerobic condition 


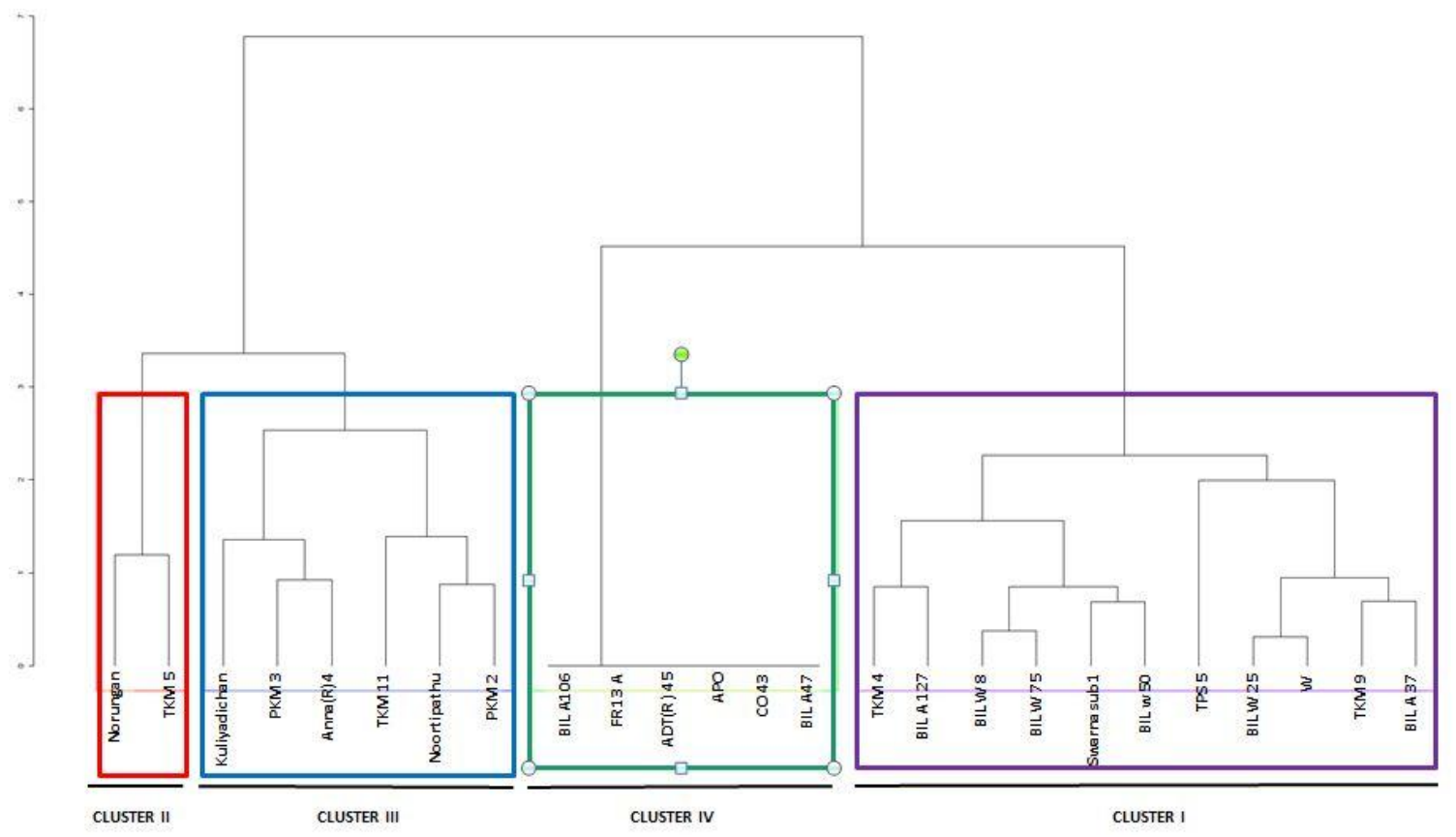

Fig.5 Dendrogram using Agglomerative Clustering Method

Whereas, globally popular donors for drought and submergence tolerance viz., Apo and FR13A with extremely different tolerance mechanism for concerned abiotic stresses formed a common group(cluster IV)along with ADT (R) 45, CO43, BIL A 47, , and BIL A 106 which recorded absence of coleoptile emergence.

These results of absence of coleoptile emergence under anaerobic condition in FR13 A and Co43 were similar to the findings of Partheeban et al., 2017 and Atwell et al., 1982 on importance of active cell division and curical period of oxygen requirement during the first $48 \mathrm{~h}$ of submergence for coleoptile emergence.

Since cellular expansion consumes less energy than cell division, the latter is the main process governing elongation under anoxia (Magneschi and Perata, 2009). This physiological mechanism explains the importance of understanding the genetic makeup of particular genotype to carry out cell division and expansion in absence of oxygen.
In contrast, submergence tolerant variety Swarna Subl with SUB 1A gene from FR 13A was grouped in cluster I along with drought tolerant donor Wayrarem with major drought QTL 12.1 (yield under drought), four BILs of ADT (R) $45 \times$ Wayrarem possessing DTY 12.1 and BILs of ADT (R) $45 \times$ Apo possessing 3 DTYs 1.1, 3.1 and 4.1, A 37 and A 127 recorded $21 \%$ of germination.

Differential expression of AG potential among the submergence tolerant FR 13A and Swarna Sub 1 with the $S U B$ IA gene from FR $13 \mathrm{~A}$ grouped in different clusters was also suggested by Doley et al., (2018); Bordoloi and Sarma, 2018. The studies of $\mathrm{Vu}$ et al., (2010), Sarkar\&Bhattacharjee (2011) and ElHendawy et al., (2014) also established that the presence of Sub1A does not always restrict shoot elongation under submergence at the early seedling stage of rice.

Ultimately, early vigour is one of the important traits under direct seeded rice since direct seeding is known or prone to higher intensity of weed growth. Ability to elongate the coleoptile under anoxia might influence 
crop establishment in submerged fields, since coleoptile emergence and coleoptile extension plays a key role in enabling the seedlings to make contact with the atmosphere to gain access to oxygen for vigorous and complete seedling development (Huang et al., 2003).

Abiotic stresses such as drought and submergence lead to significant income and consumption losses for rice growing farmers. Present climate change urge to focus on developing multiple stress tolerant genotypes with potential to protect farmer's livelihood. Hence, the result of the present study reveals that TKM 5 and Norungan embed anaerobic germination tolerance with a record of 70-80 $\%$ germination under anoxic condition. Previous studies also recorded that these two elite genotypes possess drought tolerance.

Therefore, from the observations we speculate that these two elite lines possess drought tolerance alleles coupled with anaerobic germination tolerance. Further, mining the key regulator(s) to introgress the physiological and biochemical mechanism for coleoptile emergence and coleoptile elongation may be helpful to improve germination under anoxic condition which would lead to breed cultivars with long coleoptiles which may contribute to increasing yield potential of direct seeded rice.

\section{References}

Alpi,A., and Beevers,H. Effects of $\mathrm{O} 2$ concentration on rice seedlings. Plant Physiol. 1983; 71, 30-34.

Angaji, S., Septiningsih, E.M., Mackill, D.J., and Ismail, A.M. ().QTLs associated with tolerance of anaerobic conditions during germination in rice (Oryza sativa L.). Euphytica. 2010; 172, 159168.

Atwell,B.J., and Greenway,H.The relationship between growth and oxygen uptake in hypoxic rice seedlings. J. Exp. Bot. 1987;38, 454-466.

Atwell,B.J.,Waters,I.,and Greenway, H.The effect of oxygen and turbulence on elongation of submergence-tolerant and-in tolerant rice cultivars. J. Exp.Bot. 1982;33, 1030-1044. 5.

Bernier J, Kumar A, Ramaiah V, Spaner D, Atlin G. A large-effect QTL for grain yield under reproductive-stage drought stress in upland rice. Crop Science. 2007;47(2):507-16.

Dibosh Bordoloi, Debojit Sarma. Aerobic Versus Anaerobic Germination Performance of Selected Rice (Oryza sativa L.) Genotypes with or without Submergence Tolerance. Journal of Experimental Biology and Agricultural Sciences. 2018;6, 947958.

Doley D, Barua M, Sarma D, Barua PK. Screening and enhancement of anaerobic germination of rice genotypes by pre-sowing seed treatments. Current Science. 2018; 115: 1185-1190.

Ismail, A. M., Ella, E. S., Vergara, G. V., and Mackill, D. J. Mechanisms associated with tolerance to flooding during germination and early seedling growth in rice (Oryza sativa). Ann.Bot. 2009;103, 197-209.

Kirk GJD, Greenway H, Atwell BJ, Ismail AM, Colmer TD. Adaptation of rice to flooded soils. In: Luttge U, Beyschlag $\mathrm{W}$, Cushman J (Eds.), Progress in botany Berlin, Heidelberg: Springer, 2014; 215-253.

Kordan HA .Patterns of shoot and root growth in rice seedlings germinating under water. Journal of Applied Ecology.1974; 11: 685-690.

Magneschi L, Perata P. Rice germination and seedling growth in the absence of oxygen. Annals of Botany.2009; 103: 
181-196

Mahender A, Anandan A, Pradhan SK (2015)

Early seedling vigour, an imperative trait for direct-seeded rice: an overview on physio-morphological parameters and molecular markers. Planta 241:1027-1050.

Miro B, Ismail MA. Tolerance of anaerobic conditions caused by flooding during germination and early growth in rice (Oryzasativa L.). Front. in Pl. Sci. 2013;4 (269).

Partheeban C, Srividhya S, Raveendran M and Vijayalakshmi D. Designing New Screening Methods and Physiological Dissection of Anaerobic Stress Tolerance in Rice. Int.J.Curr.Microbiol.App.Sci.2017; 6 (5): 580-590.

Sarkar RK, Bhattacharjee B. Rice genotypes with SUB1 QTL differ in submergence tolerance, elongation ability during submergence and regeneration growth at re-emergence. Rice. 2011; 5: 1-11.

Septiningsih, E. M., Ignacio, J. C. I., Sendon, P. M. D., Sanchez, D. L., Ismail, A. M., \&Mackill, D. J. QTL mapping and confirmation for tolerance of anaerobic conditions during germination derived from the rice landrace Ma- Zhan Red. Theoretical and Applied Genetics. 2013; 126(5), 1357-1366.

Sudeepthi.K, Srinivas.T, Ravi Kumar B. N. V. S. R. Jyothula D.P.B. and Nafeez Umar S. K. Screening for Tolerance to Anaerobic Germination in Rice (Oryza sativa L.)Int.J.Curr.Microbiol.App.Sci. 2019; 8(12): 2527-2538.

Tsuji H. Growth and metabolism in plants under anaerobic conditions. Environment Control in Biology. 1973; 11: 79-84.

Turner FT, Chen CC, McCauley GN.Morphological development of rice seedlings in water at controlled oxygen levels. Agronomy Journal.1981; 73: 566-570.

Vu HTT, Manangkil OE, Mori N, Yoshida S, Nakamura C. Post-germination seedling vigor under submergence and submergence-induced SUB1A gene expression in indica and japonica rice (Oryza sativa L.). Australian Journal of Crop Science. 2010; 4: 264-272.

Yamauchi, M., Aguilar, A.M., Vaughan, D.A., and Seshu, D.V. Rice (Oryza sativa L.) germplasm suitable for direct sowing under flooded soil surface. Euphytica. 1993;67, 177-184.

\section{How to cite this article:}

Arulmozhi, R., A. JohnJoel, R. Suresh, P. Boominathan and Sathiya Bama, K. 2020. Diversity Studies for Anaerobic Germination in Rice (Oryza sativa L.). Int.J.Curr.Microbiol.App.Sci. 9(07): 763-772. doi: https://doi.org/10.20546/ijcmas.2020.907.088 